\title{
Appraisal of anti-smoking advertising by youth at risk for regular smoking: a comparative study in the United States, Australia, and Britain
}

\author{
M Wakefield, R Durrant, Y Terry-McElrath, E Ruel, GI Balch, S Anderson, G Szczypka, \\ $S$ Emery, B Flay
}

See end of article for authors' affiliations

For correspondence: M Wakefield, Director Centre for Behavioural Research in Cancer, The Cancer Council Victoria, Carlton, Victoria, Australia, 3053;

Melanie.Wakefield@

cancervic.org.au

\begin{abstract}
Objective: To compare the similarity in how youth in the United States, Australia, and Britain appraise anti-smoking advertisements with different characteristics.

Design: Each participant viewed and evaluated a set of 10 anti-smoking adverts (from an overall total of 50 adverts) in a controlled experimental context using an audience response methodology. A structured telephone interview was completed one week after viewing the adverts, in which recall and engagement with the adverts by participants was evaluated.

Subjects: 615 youths who were experimenting with smoking or were susceptible nonsmokers.

Main outcome measures: Measures of advert appraisal and engagement.

Results: Youth in the United States, Australia, and Britain responded in very similar ways to the same anti-smoking advertisements. In full multivariate models, the target audience of the advert and the advert theme were not related to the main outcome measures employed in this study. However, adverts with visceral negative or personal testimonial executional characteristics were appraised more positively by youths and were more likely to be recalled, thought about, and discussed at follow up one week later.

Conclusions: Youths in three different countries responded to anti-smoking advertisements in very similar ways, suggesting that such adverts might be more actively shared among nations. The appraisal of, and engagement with, the anti-smoking adverts, however, varied substantially depending on executional characteristics. In the design of effective anti-smoking adverts, due attention needs to be paid to those characteristics that appear to most engage youth across different social and cultural environments.
\end{abstract}

A good deal of evidence now indicates that anti-smoking advertising can be effective in reducing levels of smoking among youth..$^{1-5}$ Anti-smoking advertising has been a prominent component of tobacco control initiatives in the United States and has been associated with declines in smoking prevalence among both youth and adults in the States where such advertising has been employed. ${ }^{167}$ The use of antismoking advertising has also been an important element of tobacco control efforts in Australia since the early 1980s. These advertisements, which have most recently depicted in graphic detail the adverse health consequences of smoking, have generated high public awareness and positive responses among both youth and adults. ${ }^{8-11}$ Tobacco control programmes in Britain have also employed anti-smoking advertising with some success. ${ }^{12}$

However, not all anti-smoking advertisements are equal in terms of their efficacy in changing smoking related beliefs, attitudes, and behaviours. Indeed, a number of studies have failed to find a relationship between anti-smoking advertising and reductions in tobacco prevalence. ${ }^{2-4}$ Clearly it is important to establish the characteristics of adverts and marketing strategies that are best able to advance tobacco control objectives. Opinions vary, however, regarding just what sorts of adverts are most likely to reduce smoking among youth. Pechmann and Reibling ${ }^{13}$ suggest that messages that emphasise harm to family, and the socially unacceptable nature of smoking, are likely to be most effective, whereas Goldman and Glantz $^{14}$ argue that adverts that portray the harms caused by secondhand smoke and the duplicitous nature of the tobacco industry will be most successful. Other research indicates that highly emotional appeals that depict, in graphic detail, the adverse consequences of smoking are likely to be most effective for both youth and adults. ${ }^{15-16}$ In comparison, advertisements that emphasise youth choice, or that smoking is uncool, such as those developed by Philip Morris, tend to be rated poorly by youth ${ }^{17}$ and may have a counterproductive effect on tobacco control objectives. ${ }^{18-19}$ More research is clearly required to establish the features of anti-smoking advertisements that are most likely to change smoking related beliefs, attitudes, and behaviours in ways that are commensurate with reducing the harm caused by tobacco in society.

One important, as yet unanswered, question concerns the extent to which these findings generalise across different nations. Do youth in different countries respond in the same way to anti-smoking messages and appeals? Providing an answer to this question is important for a number of reasons. By establishing the characteristics of advertisements that are effective in a variety of different contexts, the development of new anti-smoking advertisements can be undertaken in ways that are likely to best realise tobacco control objectives. Furthermore, if youth in different countries respond in similar ways to anti-smoking advertisements, a strong prima facie case can be made for the sharing of such advertisements among nations, which could result in considerable financial savings.

The present study was designed to address the way that youth at risk for regular smoking in the United States, Australia, and Britain respond to a variety of different anti-smoking advertisements. Two main research questions were posed: (a) do youth in the United States, Australia, and Britain respond in similar ways to anti-smoking advertising?; and (b) how are different anti-smoking advertisements, with different characteristics, appraised by youth in these three nations?

\section{METHOD}

Advert selection and preparation

In total, 50 advertisements were selected for inclusion in this study. These adverts were produced and aired in the United 
Table 1 Characteristics of the anti-smoking advertisements $(n=37)$

\begin{tabular}{ll}
\hline & Number (\%) \\
\hline $\begin{array}{ll}\text { Youth target audience } \\
\text { Executional characteristic }\end{array}$ & $20(54 \%)$ \\
Personal testimonial & $9(24 \%)$ \\
Visceral negative & $3(8 \%)$ \\
None of the above & $25(68 \%)$ \\
Theme & $3(8 \%)$ \\
Cessation & $5(14 \%)$ \\
Secondhand smoke & $1(3 \%)$ \\
Health benefits & $10(27 \%)$ \\
Health effects & $12(32 \%)$ \\
Industry manipulation & $3(8 \%)$ \\
Uncool & $3(8 \%)$ \\
Other & \\
\hline
\end{tabular}

States between 1997 and 2001, and were sponsored by pharmaceutical companies $(n=5)$, tobacco control programmes $(n=37)$, or tobacco companies $(n=8)$. Because adverts sponsored by pharmaceutical and tobacco companies did not have sufficient variation to study the effects of advert characteristics of primary interest in this study, analyses are only reported for responses to adverts sponsored by tobacco control programmes $(n=37)$. Each advert was coded for its primary target audience (youth or general audience), main theme (cessation methods or strategies, health effects of smoking, health benefits of quitting, secondhand smoke, exposing tobacco industry manipulation, parental or sibling guidance about tobacco, adverts portraying tobacco as "uncool", or other), and for the presence or absence of two executional characteristics: (a) personal testimonial (real people telling how smoking has affected their lives); and (b) negative visceral image (an image eliciting an unrelieved visceral "ugh!" response). Audience, theme, and executional characteristics were coded by agreement among five members of the research team. In table 1 we provide details of these different advert characteristics. Full details of the methodology employed in this study are provided by Wakefield et al. ${ }^{20}$

\section{Study participants and recruitment methods}

In total, 615 8th, 10th, or 12th grade (2th, 4th, or 6th year of secondary education in Britain) youths who were either susceptible nonsmokers or experimenting smokers ${ }^{21}$ participated in this study $(n=278$ in United States; $n=162$ in Australia; $\mathrm{n}=175$ in Britain). Participants were similarly distributed by age and sex in the three countries. Youth were recruited by market research agencies in the United States and Australia, and by the Centre for Social Marketing at the University of Strathclyde in Britain.

\section{Data collection procedure}

Data collection was carried out from March to May 2001 in the United States (Chicago and Boston), October 2002 in Australia (Melbourne), and July 2002 in Britain (Glasgow). Procedures were standardised at the three sites (except where noted). Each youth attended a rating session with 15 other youth in which they appraised 10 different adverts in a 75 minute period. Groups were facilitated by study personnel, who explained the purpose and format of the session and emphasised the importance of each participant providing honest evaluation of the adverts. Each advert was shown twice, after which the participants completed a one page rating form per advert.

Youth recorded their level of agreement with 16 emotive and appraisal statements about the advert. They were then asked to rate how good they felt each advert was via the question, "Overall, how good was this ad as an anti-smoking advertisement?" ( $1=$ not good at all, to $7=$ very good $)$. Participants in Australia and Britain received a slightly different version of this question, "Overall, I thought this ad was a very good anti-smoking advertisement" ( $1=$ strongly disagree, to $5=$ strongly agree). Youth were then asked if they had seen the advert before on television. At the end of the session participants were asked to indicate "Which one of these ads will most make you stop and think?"

A week after the rating sessions, follow up telephone calls were conducted with each participant. Participants were asked to identify which, if any, of the adverts they could recall from the rating session. For each advert recalled, they were then asked to state whether they had thought more about that advert and whether they had discussed it with anyone outside of the rating session. Finally, participants were asked if they had seen any anti-smoking adverts on television between the rating session and the follow up interview.

\section{Outcome measures and statistical analysis}

For the analyses reported in this paper, original data at the individual level were aggregated up to the advert level $(n=37)$, meaning that the responses of all youth who viewed and rated a particular advert were averaged for that advert. These responses should be interpreted as the proportion of youth related to a specific outcome. For example, for advert recall, the variable reflects the mean proportion of youth exposed to that advert that subsequently recalled the advert in the follow up interview. Outcome variables for this study included measures of appraisal and engagement. Appraisal included two measures obtained from the rating sessions: (a) how good ("Overall, I thought this ad was a very good anti-smoking advertisement"); and (b) stand out ("Which one of these ads will most make you stop and think?"). Engagement included three measures obtained during the follow up sessions: (a) recall (the proportion of youth from each rating session who recalled each specific advert at follow up); (b) thought about (the proportion of youth from each rating session who reported having thought about the advert between the rating session and follow up; and (c) discussed (the proportion of youth from each rating session who reported having discussed the advert between the rating session and follow up with someone not in the rating session).

Differences between countries on the main outcome variables were evaluated using analysis of variance, while linear regression analyses were employed to identify associations between advert characteristics and outcome variables, and to test for interaction effects between countries.

\section{RESULTS}

\section{Outcomes by country}

There were few differences between youth in the United States, Australia, and Britain on the outcome measures for anti-smoking advertisements (see table 2). On average, across the three countries, $56 \%$ of the participants rated the adverts as above average on how good, adverts were recalled on average by $37 \%$ of youth, thought about by $18 \%$, and discussed by $16 \%$. Consistent with the fact that all adverts were sourced from the United States, youth in the United States reported significantly higher prior exposure to the anti-smoking advertisements, compared with participants in either Australia or Britain. British youth were also significantly less likely to recall the anti-smoking adverts, with an average of $43 \%$ of youth in the United States and Australia recalling any given advert, compared with $27 \%$ of participants in Britain. This difference remained significant after adding prior exposure as a covariate. As can be seen by the correlations in table 3, youth in the three countries appraised the different anti-smoking adverts in very similar ways. Thus, adverts that were more likely to be chosen as the one that stands out by the Australian participants were also likely to be chosen by youth in the 
Table 2 Mean proportions (and standard deviations) for main outcome measures by country

\begin{tabular}{|c|c|c|c|c|c|c|c|c|c|}
\hline \multirow[b]{2}{*}{ Outcome Measure } & \multicolumn{3}{|l|}{ Country } & \multirow[b]{2}{*}{$\mathrm{F}$} & \multirow[b]{2}{*}{ df } & \multicolumn{4}{|c|}{ ANOVA statistics examining outcomes by country§ } \\
\hline & United States (US) & Australia & Britain & & & Overall & US $v$ Australia & US $v$ Britain & Australia $v$ Britain \\
\hline Prior exposure & $0.17(0.22)$ & $0.03(0.15)$ & $0.00(0.01)$ & 12.62 & 2 & $* * *$ & $* * *$ & $* * *$ & \\
\hline How good* & $0.61(0.23)$ & $0.53(0.26)$ & $0.56(0.26)$ & 0.83 & 2 & N.S & & & \\
\hline Stand out† & $0.12(0.14)$ & $0.12(0.15)$ & $0.12(0.15)$ & 0.03 & 2 & N.S & & & \\
\hline Recall ${ }^{\ddagger}$ & $0.42(0.17)$ & $0.43(0.21)$ & $0.27(0.20)$ & 7.33 & 2 & $\star *$ & & * * & ** \\
\hline Thought about ${ }^{\ddagger}$ & $0.20(0.14)$ & $0.20(0.14)$ & $0.14(0.14)$ & 2.10 & 2 & N.S & & & \\
\hline Discussed $^{\ddagger}$ & $0.15(0.12)$ & $0.19(0.15)$ & $0.14(0.14)$ & 0.99 & 2 & N.S & & & \\
\hline
\end{tabular}

* "How good" is measured on a scale of 1-7 in the US and 1-5 in Australia and Britain. Data presented for this variable represent the proportion of participants who viewed an advert who rated it as above average in the scale for how good.

"Stand out" is the one advert chosen out of the group of 10 adverts seen by the youth that is most likely to make them "stop and think". It is interpreted as the proportion that chose a given advert as the one that most stands out.

‡"Recall", "thought about", and "discussed" are yes/no variables. Thus, data presented represent the proportion of participants who viewed an advert, were followed up, and recalled the advert or responded "yes" to the other outcome variables.

$\S$ Post hoc comparisons were carried out using the Tukey honestly significant difference test.

${ }^{*} \mathrm{p}<0.05 ;{ }^{* *} \mathrm{p}<0.01 ;{ }^{* * *} \mathrm{p}<0.001$

United States and Britain. Moreover, even though participants in Britain were less likely to recall the advertisements, they tended to recall the same ones as youth in Australia and the United States.

In order to establish which of the adverts were most likely to be effective in advancing tobacco control objectives, an "advert impact" score was constructed for each advert based on the summed combination of scores (that is the sum of proportions) on three of the main outcome measures: how good, stand out, and discussed. These measures were chosen to provide information based both on advert appraisal and advert engagement. We selected only one measure of engagement (discussed) because recall and thought about were so highly correlated with it (and each other). The internal reliability of this scale was high $(\alpha=0.84)$. As can be seen in table 4 , out of the 10 adverts that received the highest impact scores, four were aimed at a youth audience, and themes included health effects, secondhand smoke, industry manipulation, and other. The four adverts with the highest advert impact scores all featured either personal testimonial or visceral negative executional characteristics and all were rated as very good anti-smoking adverts by over $90 \%$ of the participants. All of these adverts were also thought about by over $40 \%$, and

Table 3 Correlations between United States (US), Australian, and British participants for main outcome measures ( $n=37$ adverts)

\begin{tabular}{|c|c|c|c|}
\hline \multirow[b]{2}{*}{ Outcome Variables } & \multicolumn{3}{|l|}{ Country } \\
\hline & US & Australia & Britain \\
\hline \multicolumn{4}{|l|}{ Stand out } \\
\hline US & - & & \\
\hline Australia & $0.89 * * *$ & - & \\
\hline Britain & $0.92 * * *$ & $0.89 * * *$ & - \\
\hline \multicolumn{4}{|l|}{ How good } \\
\hline US & - & & \\
\hline Australia & $0.93 * * *$ & - & \\
\hline Britain & $0.87^{* * *}$ & $0.89 * * *$ & - \\
\hline \multicolumn{4}{|l|}{ Recall } \\
\hline US & - & & \\
\hline Australia & $0.87^{* * *}$ & - & \\
\hline Britain & $0.82 * * *$ & $0.79 * * *$ & - \\
\hline \multicolumn{4}{|l|}{ Thought about } \\
\hline US & - & & \\
\hline Australia & $0.69 * * *$ & - & \\
\hline Britain & $0.78 * * *$ & $0.75^{* * *}$ & - \\
\hline \multicolumn{4}{|l|}{ Discussed } \\
\hline US & - & & \\
\hline Australia & $0.67 * * *$ & - & \\
\hline Britain & $0.78^{* * *}$ & $0.60 * * *$ & - \\
\hline
\end{tabular}

discussed by over $36 \%$ of youth who saw them, suggesting that they have qualities that are most likely to influence smoking related attitudes, beliefs, and behaviours.

\section{Multivariate relationships for tobacco control adverts}

Full multivariate models were specified for the 37 tobacco control adverts as depicted in table 5. As these analyses included a relatively small $\mathrm{n}$ value, we indicate if relationships were observed at the $\mathrm{p}<0.10$ level (non-standard significance), as well as standard significance levels of $p<0.05$. The target audience of the adverts was not significantly related to any of the outcome measures employed in this study. However, adverts with personal testimonial and visceral negative executional characteristics significantly increased the proportion of participants who rated such adverts as above average on how good, selected them as the one that stands out, and who recalled, thought about, and discussed them at follow up (see table 5).

Prior exposure was also significantly positively related to ratings of how good, stand out, and advert recall, but not to the other outcome variables. There were few significant relations between advert theme and the outcome measures. Using adverts with the theme of health effects as the referent, adverts with a health benefits or secondhand smoke theme marginally increased the proportion of youth that rated them as the one that stands out; and adverts with an uncool theme were marginally less likely to be discussed at follow up.

As we found with the bivariate models discussed previously, the only significant relationship between country and the outcome measures was that the proportion of participants who recalled adverts in Britain was significantly lower. Multivariate models that included all interactions between country, audience, executional characteristics, and advert themes found no systematic significant effects.

\section{DISCUSSION}

The results of the study indicate that anti-smoking advertisements sponsored by tobacco control programmes are appraised and engaged in very similar ways by youth in the United States, Australia, and Britain. The only significant difference found was that youth in Britain were less likely to recall any specific advert when followed up a week later. This finding could not be explained by differences in prior exposure to the adverts or in the amount of time elapsed between the rating session and the follow up call, and probably relates to subtle differences in either the sample or methodology employed (although care was taken to standardise procedures in the three countries).

In this study, the executional characteristics of adverts provided the strongest and most consistent effect on measures of 
Table 4 Advertisements most positively appraised and engaged by participants*

\begin{tabular}{|c|c|c|c|c|c|}
\hline Score & Sponsor $\ddagger$ & $\begin{array}{l}\text { Executional } \\
\text { characteristic } \S\end{array}$ & $\begin{array}{l}\text { Youth } \\
\text { audience }\end{array}$ & Theme & Description \\
\hline 1.90 & CA & VN, PT & No & Health effects & $\begin{array}{l}\text { Shows a man who has had a laryngectomy cleaning his stoma. Text introduces } \\
\text { man as a cancer patient who has lost his lung and vocal chord from smoking; } \\
\text { advert closes over sound of man rasping }\end{array}$ \\
\hline 1.77 & AUS/MA & VN & No & Health effects & $\begin{array}{l}\text { Man lights cigarette on stove; surgeon squeezes fatty deposits from a young } \\
\text { smoker's aorta; tag line: "Every cigarette is doing you damage" }\end{array}$ \\
\hline 1.74 & CA & PT & No & Secondhand smoke & $\begin{array}{l}\text { Older man talks about his wife who always used to tell him not to smoke. Man } \\
\text { relates how he didn't die from his smoking, but his wife did. Text appears: } \\
\text { "Second hand smoke kills more than } 53000 \text { people every year" }\end{array}$ \\
\hline 1.54 & MA & PT & No & Health effects & $\begin{array}{l}\text { Ex-model - Janet Sackman - who has lost her vocal chords from smoking, talks in } \\
\text { a croaky voice about tobacco advertising and the health effects of smoking }\end{array}$ \\
\hline 1.51 & SF & None & No & Other & $\begin{array}{l}\text { Documentary style images of tobacco farming in a developing nation; voice over } \\
\text { describes how food crops have been replaced by tobacco, which is farmed with } \\
\text { the use of harmful chemicals. Shot of a young girl in a hospital bed; voice/text } \\
\text { states: "It is not just smokers who are dying from tobacco" }\end{array}$ \\
\hline 1.41 & MA & PT & Yes & Health effects & $\begin{array}{l}\text { Young woman - Pam Laffin - who has had a lung removed and has to take } \\
\text { medication for the rest of her life says that she "started to smoke to look older, and } \\
\text { I am sorry to say - it worked" }\end{array}$ \\
\hline 1.32 & ALF & None & Yes & Industry manipulation & $\begin{array}{l}\text { Outside a major tobacco company, teens pull bodybags out of truck and stack in } \\
\text { front of building; Sign: every day } 1200 \text { people die from smoking }\end{array}$ \\
\hline 1.31 & MA & None & No & Secondhand smoke & $\begin{array}{l}\text { Black and white image of cigarette burning; reverse image of smoke going into } \\
\text { lungs; man talks about the risks of secondhand smoking: "there is a warning on } \\
\text { cigarette packs for people who smoke, where do you think they should put the } \\
\text { warning for people who breathe?" }\end{array}$ \\
\hline 1.23 & MA & PT & Yes & Industry manipulation & Teenage girl talks about her addiction to cigarettes. She wishes she could quit \\
\hline 1.11 & $A Z$ & None & Yes & Secondhand smoke & $\begin{array}{l}\text { Two young kids and a small dog at a park; one kid is smoking and talking about } \\
\text { how smart dogs are, as smoke trails into dog's face. Dog urinates on cigarette and } \\
\text { trots off }\end{array}$ \\
\hline \multicolumn{6}{|c|}{$\begin{array}{l}\text { *Copies of these advertisements are available from the Media Campaign Resource Centre, Office on Smoking and Health, U.S. Centers for Disease } \\
\text { Control and Prevention. } \\
\text { tThe advert impact score represents the mean of the summed totals for US, Australian, and British participants for the variables how good, stand out, and } \\
\text { discussed. } \\
\text { fCA, California; MA, Massachusetts; AUS, Australia; SF, San Fransisco; ALF, American Legacy Foundation; AZ, Arizona. } \\
\text { SVN visceral negative: PT personal testimonial. None neither of these }\end{array}$} \\
\hline
\end{tabular}

advert appraisal and engagement. The presence of personal testimonial or visceral negative executional characteristics significantly increased the proportion of participants who rated adverts as very good anti-smoking adverts, selected them as the one that most stands out, and who recalled, thought about, or discussed such adverts at follow up. Moreover, of the 10 adverts with the highest impact scores, six featured one or more of these two executional characteristics. Previous research has highlighted the role of personal testimonials in delivering persuasive anti-smoking messages, ${ }^{6}{ }^{17}$ and the efficacy of negative visceral images is supported by mass communications theory that emphasises the importance of emotional engagement in communicating messages to audiences who may not be especially interested in

Table 5 Multivariate models examining youth cognitive engagement with tobacco control anti-smoking advertising $(n=37) \dagger$

\begin{tabular}{|c|c|c|c|c|c|c|c|c|c|c|}
\hline \multirow[b]{3}{*}{ Independent variable } & \multicolumn{10}{|c|}{ Dependent variable } \\
\hline & \multicolumn{2}{|c|}{ How good } & \multicolumn{2}{|c|}{ Stand out } & \multicolumn{2}{|l|}{ Recall } & \multicolumn{2}{|c|}{ Thought about } & \multicolumn{2}{|c|}{ Discussed } \\
\hline & B & $\mathrm{p}$ & B & $\mathrm{p}$ & B & $\mathrm{p}$ & B & $\mathrm{p}$ & B & $\mathrm{p}$ \\
\hline Intercept & 0.49 & $\star * *$ & 0.02 & & 0.35 & $* * *$ & 0.14 & $* * *$ & 0.13 & *** \\
\hline Australia & -0.04 & & 0.02 & & 0.01 & & 0.00 & & 0.02 & \\
\hline Britain & -0.02 & & 0.03 & & -0.14 & ** & -0.05 & & -0.02 & \\
\hline Youth target audience & -0.03 & & 0.00 & & 0.01 & & 0.00 & & -0.01 & \\
\hline Personal testimonial execution & 0.29 & $* * *$ & 0.14 & $* * *$ & 0.20 & $* * *$ & 0.14 & $* * *$ & 0.13 & $* * *$ \\
\hline Visceral negative execution & 0.25 & ** & 0.22 & $* * *$ & 0.21 & $* * *$ & 0.21 & $* * *$ & 0.19 & $\star * *$ \\
\hline Prior exposure & 0.35 & ** & 0.15 & + & 0.18 & + & 0.10 & & 0.02 & \\
\hline \multicolumn{11}{|l|}{ Theme } \\
\hline Health effects (referent) & (ref) & & (ref) & & (ref) & & (ref) & & (ref) & \\
\hline Cessation & -0.11 & & -0.03 & & -0.07 & & -0.10 & & -0.05 & \\
\hline Secondhand smoke & 0.11 & & 0.12 & + & 0.06 & & 0.08 & & 0.06 & \\
\hline Health benefits & 0.09 & & 0.08 & + & 0.06 & & 0.05 & & 0.03 & \\
\hline Industry manipulation & -0.04 & & 0.01 & & -0.06 & & 0.00 & & -0.03 & \\
\hline Uncool & -0.14 & & -0.07 & & -0.09 & & -0.07 & & -0.10 & + \\
\hline Other & -0.02 & & 0.10 & & -0.10 & & -0.06 & & -0.08 & \\
\hline
\end{tabular}

$+\mathrm{p}<0.10 ;{ }^{*} \mathrm{p}<0.05 ;{ }^{*} \mathrm{p}<0.01 ;{ }^{*}{ }^{*} \mathrm{p}<0.001$

tFamily guidance theme not included as no tobacco control adverts utilised this theme.

Note: there were no systematic significant interactions between country, audience, executional

characteristics, and advert theme on any of the outcome measures. 
the subject matter. ${ }^{1622}$ Although marketing theory and some researchers ${ }^{13} 23$ suggest that adverts should be targeted towards specific audiences, there was no effect of target audience in this study. That is, adverts that were aimed at youth were not appraised or engaged in different ways from those aimed at a more general audience. Indeed, it is interesting to note that the four advertisements that received the highest advert impact scores (see table 4 ) were all targeted at a general audience and included vivid portrayals of the negative health consequences of smoking (or secondhand smoke). Despite the widespread idea that young people feel they are immortal and therefore an emphasis on the long term health effects of smoking may be inappropriate, research has suggested that threat appeals may be just as effective with youth as they are with adults. ${ }^{24}$ Although the outcome measures that we employed did not allow us to assess how different adverts influence smoking related attitudes, beliefs, and behaviours, adverts that employed personal testimonial and visceral negative executional characteristics that emphasised the harms of smoking were appraised positively and engaged by youth in all three countries.

One reason why disagreement remains regarding the most effective characteristics of anti-smoking adverts is that such advertisements are complex, multifaceted stimuli that can be rated on a wide range of different dimensions, few of which have been systematically evaluated in research. The different physical, social, and cultural environments in which adverts are placed provides another potential explanation for why such disagreement remains: some adverts might be more effective in some, but not other, cultural historical contexts. However, on the basis of the results presented in this study, it seems clear that youth in the comparatively similar cultural environments of the United States, Australia, and Britain appraise and engage anti-smoking advertisements in very similar ways.

These findings should encourage the open exchange of anti-smoking adverts between such countries, effectively extending the often stretched budgets of tobacco control programmes. Furthermore, this study suggests that tobacco control programmes might seriously consider the use of adverts that test most effectively with people in other similar countries. The evaluation of anti-smoking adverts in more diverse cultural environments is one possible extension of the research presented here, which could pave the way for the more global use of mass media tobacco control campaigns.

\section{ACKNOWLEDGEMENTS}

This study was funded by the United States National Cancer Institute State and Community Tobacco Control Intervention Program, Grant \# RO l CA86273-01. The study was conducted while Dr Wakefield was the recipient of a VicHealth Senior Research Fellowship. We thank Kim McLeod at The Cancer Council Victoria, Kate Clegg-Smith at the University of Illinois, and Laura McDermott at the University of Strathclyde for moderating the rating sessions. We also thank Jason Boulter at The Cancer Council Victoria, Kathryn Angus at the University of Strathclyde, and Sandy Slater at the University of Illinois for research administration support. In addition we acknowledge the contribution of researchers who gave early input into study design and development of measures, including Gerard Hastings, Lois Biener, Phillip Klafta, David Hill, William Wells, Kim Worden, and Frank Chaloupka.

\section{DISCLOSURE}

Melanie Wakefield is a senior editor of Tobacco Control. She was excluded from editor-reviewer correspondence and was not included in the editorial decision making process for this manuscript.

\section{Authors' affiliations}

M Wakefield, R Durrant, The Cancer Council Victoria, Melbourne, Australia

Y Terry-McElrath, University of Michigan, USA

E Ruel, GI Balch, University of Illinois, Chicago, USA

$S$ Anderson, University of Strathclyde, Scotland, UK

G Szczypka, S Emery, B Flay, University of Illinois, Chicago, USA

\section{REFERENCES}

1 Baver UE, Johnson TM, Hopkins RS, et al. Changes in youth cigarette use and intentions following implementation of a tobacco control program: findings from the Florida youth tobacco survey, 1998-2000. JAMA 2000:284:723-8.

2 Friend K, Levy DT. Reductions in smoking prevalence and cigarette consumption associated with mass-media campaigns. Health Education Research 2002;17:85-98.

3 Siegel $M$, Biener $L$. The impact of an antismoking media campaign on progression to established smoking: results of a longitudinal youth study. Am J Public Health 2000;90:380-6.

4 Wakefield $M$, Flay $B$, Nichter $M$, et al. Effects of anti-smoking advertising on youth smoking: a review. Journal of Health Communication, 2003:8:229-47.

5 Sly DF, Trapido E, Ray S. Evidence of the dose effects of an antitobacco counteradvertising campaign. Prev Med 2002;35:511-8.

6 Biener L, Harris JE, Hamilton W. Impact of the Massachusetts tobacco control programme: population based trend analysis. BM 2000;321:351-4.

7 Sly D, Hopkins R, Trapido E, et al. Influence of a counteradvertising media campaign on initiation of smoking: the Florida "truth" campaign. Am J Public Health 2001;91:233-8.

8 Pierce JP, Macaskill P, Hill D. Long-term effectiveness of the early mass media led antismoking campaigns in Australia. In Hornik RC, ed. Public health communication: evidence for behaviour change. Mahwah, NJ: Lawrence Erlbaum Associates, 1990;57-70.

9 Hill D, Carroll T. Australia's National Tobacco Campaign Tob Control 2003;12(suppl II):ii9-14.

10 Wakefield $M$, Freeman J, Donovan R. Recall and response of smokers and recent quitters to the Australian National Tobacco Campaign Tob Control 2003; 12(suppl II):ii 15-22.

11 White V, Tan N, Wakefield $M$, et al. Do adult focused anti-smoking campaigns have an impact on adolescents? The case of the Australian National Tobacco Campaign Tob Control 2003;12(suppl II):ii23-9.

12 McVey D, Stapleton J. Can anti-smoking television advertising affect smoking behaviour? Controlled trial of the Health Education Authority for England's anti-smoking TV campaign. Tob Control 2000;9:273-82.

13 Pechmann C, Reibling ET. Planning an effective anti-smoking mass media campaign targeting adolescents. Journal of Public Health Management Practice 2000;6:80-94

14 Goldman LK, Glantz SA. Evaluation of anti-smoking advertising campaigns. JAMA 1998;279:772-7.

15 Hill D, Chapman S, Donovan R. The return of scare tactics. Tob Control 1998;7:5-8

16 Witte K, Allen M. A meta-analysis of fear appeals: implications for effective public health campaigns. Health Educ Behav 2000:27:591-615.

17 Biener L. Anti-tobacco advertisements by Massachusetts and Philip Morris: what teenagers think. Tob Control 2002; 11 (Suppl II):ii43-6.

18 Farrelly MC, Healton CG, Davis KC, et al. Getting to the truth: Evaluating national tobacco countermarketing campaigns. Am J Public Health 2002:92:901-7.

19 Landman A, Ling PM, Glantz SA. Tobacco industry youth smoking prevention programs: protecting the industry and hurting tobacco control. Am J Public Health 2002;92:917-30.

20 Wakefield M, Balch Gl, Terry-McElrath Y, et al. Assessment of youth responses to anti-smoking ads: description of a research protocol. ImpacTeen Research Paper Series. Chicago, IL: ImpacTeen; 2002;No 23.

21 Choi WS, Gilpin EA, Farkas A, et al. Determining the probability of future smoking among adolescents. Addiction 2001;96:313-23.

22 Hafstad A, Aaro LE, Engeland A, et al. Provocative appeals in anti-smoking mass media campaigns targeting adolescents - the accumulated effects of multiple exposures. Health Education Research 1997:12:227-36.

23 Beaudoin, CE. Exploring antismoking ads: appeals, themes, and consequences. Journal of Health Communication 2002;7: 123-37.

24 Henley N, Donovan RJ. Young people's response to death threat appeals: do they really feel immortal. Health Education Research 2003;18:1-14 